\title{
The Smart City Energy Infrastructures at the Savona Campus of the University of Genoa
}

\author{
Stefano Bracco*, Federico Delfino*o, Paola Laiolo ${ }^{\circ}$, Mansueto Rossi* \\ *Department of Naval, Electrical, Electronic and Telecommunication Engineering \\ ${ }^{\circ}$ Management Center of Savona Campus facilities \\ University of Genoa \\ Via all’Opera Pia 11a, 16145 - Genova \\ *stefano.bracco@unige.it
}

\begin{abstract}
This paper presents ongoing research activities and technology upgrades carried out by the Power System Research team of the University of Genoa on the Smart City test-bed facilities installed at the Savona Campus. These facilities consist of a Smart Polygeneration Microgrid (SPM) feeding the Campus, of a Smart Energy Building (SEB) connected to the SPM and acting as a "prosumer" and of an Energy Management System (EMS) controlling the Campus generating units and thermal and electrical loads. The SPM, initially set up as a grid-tied system, is now subjected to further improvements in order to be operated in islanded mode. The paper shows that all the aforementioned infrastructures constitute a real example of how to build a sustainable smart city.
\end{abstract}

Keywords-Smart city; microgrids; sustainability; energy management; power system planning.

\section{INTRODUCTION}

The smart cities of the future will be more and more characterized by the interaction between smart grids/microgrids and smart buildings [1-6]. As assessed by Kolokotsa in [7], smart grids are modern electric power grid infrastructures for enhanced efficiency and reliability through automated control, high-power converters, modern communications infrastructure, sensing and metering technologies, and modern energy management techniques based on the optimization of demand, energy and network availability. The demand, both electrical and thermal, is represented by different entities that can be divided into two main groups: traditional consumers and innovative prosumers, these last being both producers and consumers. In the aforementioned scenario, new buildings will be more and more energy prosumers, characterized by highefficiency generation units and energy-efficient appliances.

With regard to electrical/thermal power generation units to be used in the smart city context, different technologies are available on the market $[8,9]$, among which the most profitable are: Combined Cooling Heating and Power units (CCHP), heat pumps, absorption chillers, and renewable power plants (mainly thermal solar collectors, photovoltaic panels, biomass and wind). In particular, smart city applications require the installation of small size renewable and/or fossil-fueled power plants, distributed over the territory next to the end-users, that substitute centralized power stations [10]. Lund et al. in [11] investigate the design of energy systems to increase the use of renewable sources, such as photovoltaics and wind power, in cities: they show how through smart energy system design, it is possible to reach renewable source higher shares of electricity consumption compared to just integrating the aforementioned sources in a traditional way into the energy system.

A smart city equipped with smart microgrids and smart buildings need to be managed by efficient and reliable Energy Management Systems (EMS) [12-16]. As highlighted by Calvillo et al. in [17], energy management is one of the most demanding issues within such urban centres owing to the complexity of the energy systems and their vital role. As reported in [17], the smart city is intended to deal with or mitigate, through the highest efficiency and resource optimization, the problems generated by rapid urbanization and population growth, such as energy supply, waste management, and mobility. Consequently, not only energy issues are fundamental, but also waste management and mobility aspects have to be taken into account $[18,19]$.

The paper is organized as follows. Section II briefly outlines the activities of the Power System Research team at the Savona Campus, focusing on the "Energia 2020" project; Section III is relative to the description of the Smart Polygeneration Microgrid project, whereas in Section IV the Smart Building project is briefly illustrated. Section V is focused on the Savona Campus Energy Management System, while in Section VI conclusive remarks are reported.

\section{The ACTIVITIES OF THE POWER System ReseARCH TEAM AT THE SAVONA CAMPUS}

The Savona Campus of the University of Genoa in Italy, developed over an area of about $60000 \mathrm{~m}^{2}$, is $2 \mathrm{~km}$ far from the Savona city center. It hosts research laboratories of the University, research centers and SMEs, as well as the CIMA Foundation - National Centre for Civil Protection on hydrogeological risk. Approximately 1700 students frequent the Campus where different courses related to the Polytechnic School, the Medicine School and the Social Sciences School are offered. The Savona Campus is also provided with a library, a cafeteria, sports facilities, student residences, and other services. 
One of the main aspects that characterize the Savona Campus are the research activities in the sustainable energy sector. In this context, it is worth mentioning the "Energia 2020 " project of the University of Genoa that is an important R\&D project related to the concepts of Sustainable Energy (renewable energy, energy saving and reduction of $\mathrm{CO}_{2}$ emissions) and Smart City [14, 15, 18, 20]. The project, which has been developed thanks to a full public financing, is designed to install within the Savona Campus innovative energy systems aimed at reducing operating costs, $\mathrm{CO}_{2}$ emissions and, at the same time, at creating a comfort working environment for the Campus users.
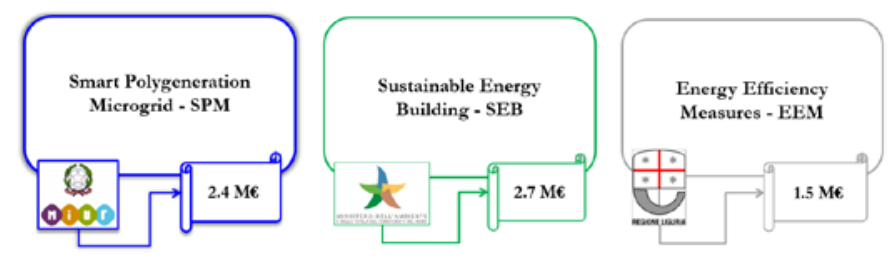

Fig. 1 The branches of the "Energia 2020” project.

As shown in Fig. 1, the "Energia 2020" project consists of three different subprojects:

\section{- Smart Polygeneration Microgrid (acronym: SPM)}

- Smart Energy Building (acronym: SEB)

- Energy Efficiency Measures (acronym: EEM).

In particular, the SPM is relative to the construction of a smart microgrid to provide both electrical and thermal energy to the Savona Campus [14, 15, 18, 20]. The SPM has been inaugurated at the beginning of February 2014 and in 2015 the European Electricity Grid Initiative (EEGI) label has been assigned to it. The SPM has been funded by the Italian Ministry for Education, University and Research with 2.4 M€.

The SEB deals with the construction of a sustainable smart building connected to the SPM as a prosumer. The SEB is under construction and works will be finished at the beginning of 2017. The SEB has been funded by the Italian Ministry of the Environment and Protection of Land and Sea with 2.7 M€.

Finally, the EEM is relative to some interventions necessary to upgrade some existing buildings of the Savona Campus in order to both increase their energy performance and guarantee the safety of users. The EEM has been funded by the Liguria Region with 1.5 M€

The "Energia 2020" project is managed by the University Service Center (acronym: CENS) which is the entity that coordinates the Savona Campus activities. The research activities developed on the SPM and SEB infrastructures are carried on by the Power System Research team of the University of Genoa that operates at the Savona Campus. The team is composed of around ten researchers and technicians whose core competences are in the fields of power systems, electric machines and energy systems. Its research activities concern with: electrical networks and power systems modeling and control; integration of renewables and storage systems into the power delivery system; planning, design and management of smart microgrids; simulation and optimization of energy systems; power systems engineering and economics. On such topics the team developed in the past and is now working on several scientific projects, in partnerships with industry players and funded by public bodies (National and Regional Authorities, EU Commission) and private institutions (industries, SMEs).

As aforementioned, the Savona Campus is becoming a real pilot facility where it will be possible to test the energy infrastructures of the smart city. Consequently, the research activities will be more and more focused on the following topics: smart grids and polygeneration microgrids, renewable power plants and storage systems, smart buildings, smart public lighting and energy management systems. Moreover, at the Savona Campus in the next years other important projects will be developed in the following fields: broad band, physical and cyber security, health and wellness for the citizens, food and nutrition management.

\section{The SMART Polygeneration Microgrid}

\section{A. The concept}

The SPM is a 3-phase low voltage (400 V line-to-line) "intelligent" distribution system coupled with a thermal network [14, 15, 18, 20].

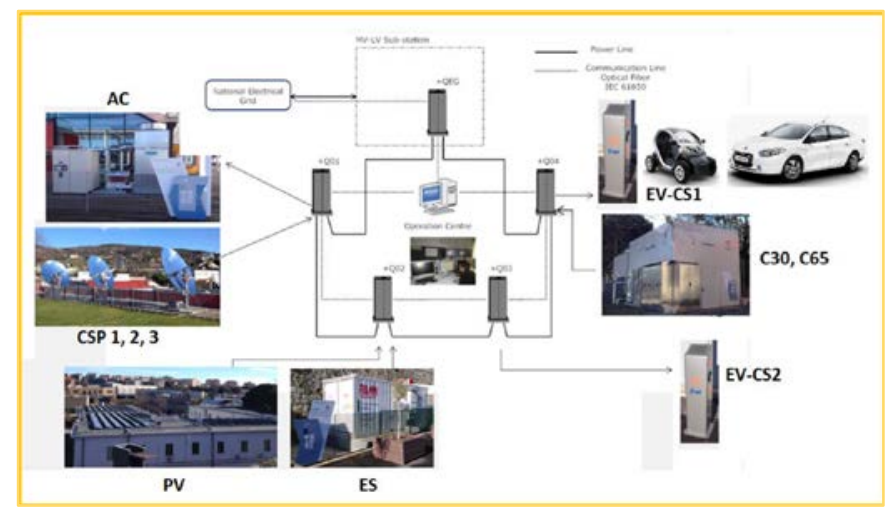

Fig. 2 The SPM electrical configuration.

In Fig. 2 the electrical configuration of the microgrid is reported, whereas in Fig. 3 the pipelines of the heat distribution network are sketched on the Savona Campus map, together with the location of the different power plants that compose the SPM. The electrical grid topology is that of a ring (600 m long) with one main switchboard (QEG) and four other switchboards (Q01, Q02, Q03, Q04) to which the power plants are connected. A dedicated $\mathrm{MV} / \mathrm{LV}$ transformer, linked to the MV busbar of the Savona Campus MV/LV substation, connects the SPM to the distribution network. All the buildings are not directly connected to the SPM: in this way the SPM can be easily disconnected from the other systems without compromising the electricity supply to the buildings. The SEB 
will be the first building that will be directly connected to the SPM.

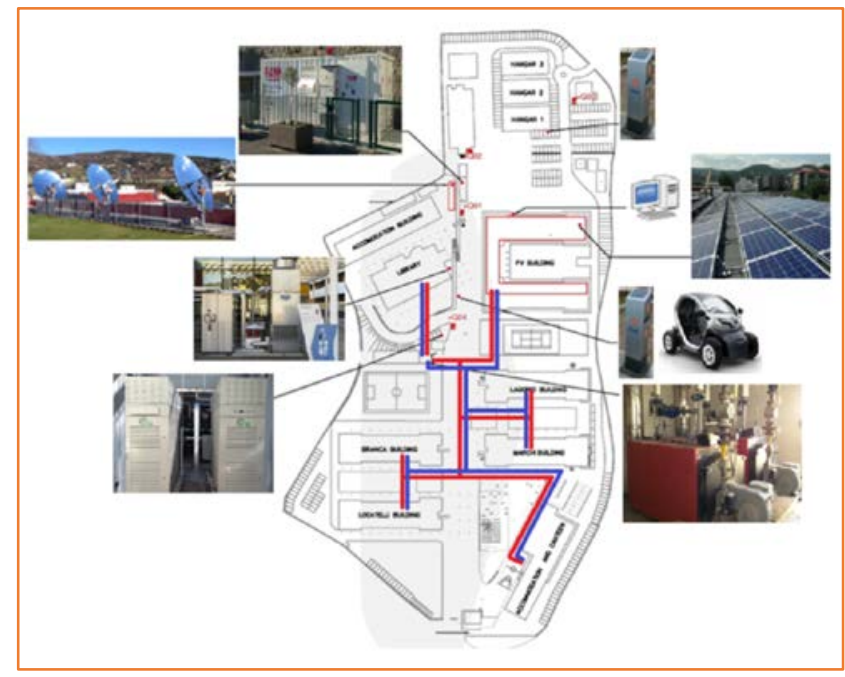

Fig. 3 The heat distribution network and the SPM power plants.

\section{B. The technologies}

The SPM is composed of the following technologies:

- three $\mu \mathrm{CHP}$ (micro Combined Heat and Power) gas turbines (160 kW $\mathrm{kW}_{\mathrm{e}}, 284 \mathrm{~kW}_{\mathrm{th}}$ ) Capstone C30 and C65 models;

- two natural gas boilers (900 $\left.\mathrm{kW}_{\mathrm{th}}\right)$;

- two photovoltaic (PV) fields $\left(80+15 \mathrm{~kW}_{\mathrm{p}}\right)$ made of polycrystalline modules;

- three Concentrating Solar Systems (CSP) equipped with Stirling engines (3 $\left.\mathrm{kW}_{\mathrm{e}}, 9 \mathrm{~kW}_{\mathrm{th}}\right)$;

- a water/lithium bromide absorption chiller (70 kW);

- two electrical storage systems $\left(\mathrm{Na}-\mathrm{NiCl}_{2}, 140 \mathrm{kWh}_{\mathrm{e}}\right.$, and Liions, $25 \mathrm{kWh}_{\mathrm{e}}$ );

- two battery electric vehicle (BEV) charging stations.
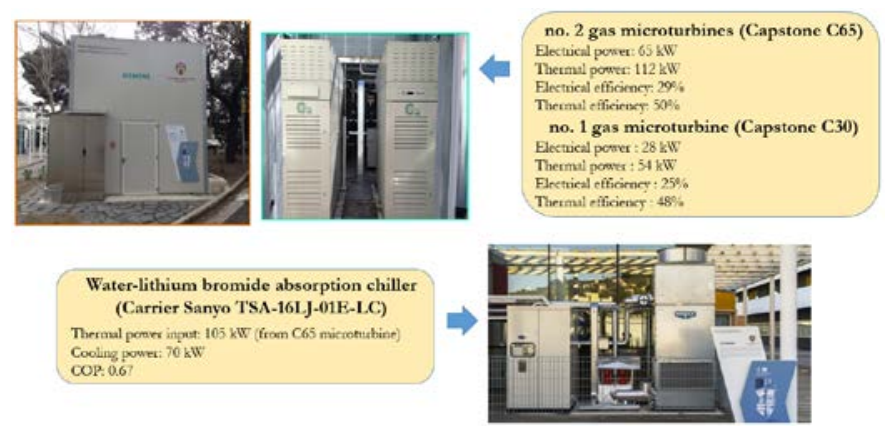

Fig. 4 The microturbines and the absorption chiller in the SPM.

In Fig. 4 the main features of the microturbines and of the absorption chiller are reported, whereas in Fig. 5 the attention is focused on the renewable power plants, the storage systems and the e-mobility infrastructures.

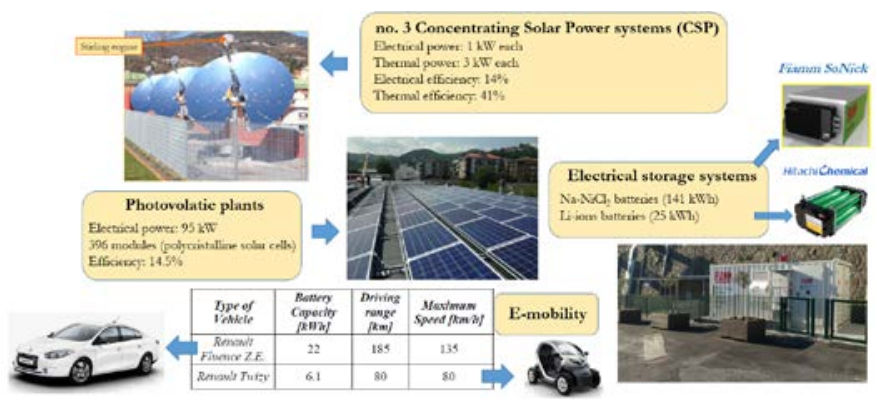

Fig. 5 The renewable power plants, the storage systems and the emobility in the SPM.

\section{THE SMART ENERGY BUILDING}

The SEB will be an environmentally sustainable building connected to the SPM, equipped by renewable power plants and characterized by energy efficiency measures [14]. In particular, the following technologies will be installed in the SEB:

- a geothermal heat pump (45 $\mathrm{kW}_{\mathrm{th}}, 8$ probes);

- a back-up traditional heat pump;

- a photovoltaic (PV) field (23 $\left.\mathrm{kW}_{\mathrm{p}}\right)$;

- thermal solar collectors for the domestic hot water production;

- a rainwater collection system.
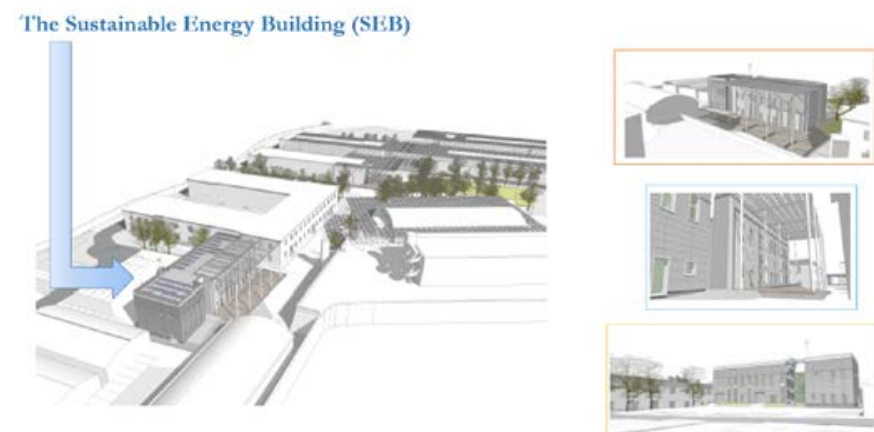

Fig. 6 The SEB location inside the Savona Campus.

Moreover, the SEB will be characterized by: high performance thermal insulation materials for building applications, ventilated facades, LED lighting systems, etc. In Fig. 6 and in Fig. 7 some sketches of the new building are reported. The ground floor of the SEB will host the U-GYM (an innovative gym also equipped with bikes generating electricity), the smart grid and the distributed generation laboratories. On the other hand, the first floor will be occupied by offices, a meeting room and a domotic laboratory where it will be possible to test innovative home appliances. 
All the aforementioned infrastructures will be real-time monitored in the control room of the SPM.

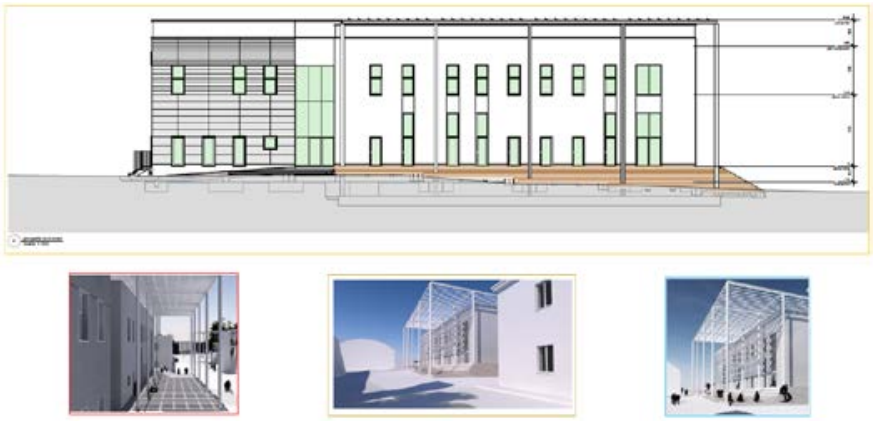

Fig. 7 Some sketches of the SEB.

\section{The SAVOna CAmpus EnERgy Management System}

The SPM is daily operated by an Energy Management System (EMS) with the aim of minimizing operating costs, that are given by the sum of the natural gas expense (to feed microturbines and boilers) and of the electricity expense (due to the electricity withdrawn from the public grid) [14-16, 18, 20]. In the next year, the SEB will be managed by the aforementioned EMS too.

The EMS acts as the "intelligence" of the energy infrastructures and interacts with both the hardware in field (with different communication protocols) and a variety of software tools for simulation and control. The EMS uses as inputs:

- cost functions (natural gas price, electricity price, plant maintenance cost, fees for the electricity local production, etc.);

- technical and environmental constraints (related to the performance of power plants: microturbine primary and thermal power as a function of generated electrical power, behavior of microturbines and boilers at partial loads, minimum/maximum values of power generated by the different plants, etc.);

- the Savona Campus electrical and thermal load forecast (estimated on the basis of weather forecast and historical data);

- estimation of power production from renewable sources basing on weather forecast and historical data.

The goal of the EMS is that of scheduling the operation of fossil-fueled power plants (microturbines and boilers) and electrical storage systems with the aim of minimizing daily operating costs and/or $\mathrm{CO}_{2}$ emissions. The EMS's objective function can also take into account other issues such as the minimization of the electricity withdrawn from the public grid or the maximization of the self-consumption. The optimization algorithm is characterized by a time horizon of 24 hours, with 15 minutes time intervals. It is also important to mention the flexibility of the EMS in real-time: basing on the dispatched plan, any deviation that occurs during operation concerning with the energy exchange with the external network is shared at minimum cost among generators, storage systems, and loads, which can be controlled, so that the planned value can be met. For instance, if the photovoltaic production is lower than the expected one, the lack of energy is compensated by increasing the power delivered by the energy storage system or by the microturbines.

In Figs. 8-12 the recorded electrical and thermal load profiles of some typical days are plotted, highlighting how the different power plants have been managed by the EMS. Figure 8 refers to a typical summer working day (Friday - July 10, 2015). The electrical load (in light blue negative bars) attains maximum values (around $300 \mathrm{~kW}$ ) at midday, whereas the base load of $100 \mathrm{~kW}$ (almost constant during the entire year) occurs during the night. The power plants are managed as follows:

- the two boilers are off (since during summer no thermal energy is required to heat the buildings);

- $\quad$ only one of the three gas turbines (olive bars in Fig. 8) is in operation from 7 a.m. to 12 a.m. (it provides electricity to the SPM grid and thermal energy to the absorption chiller that cools the library - this last closes at 2 p.m. on Friday);

- the contribution of CSP plants is limited and thus it is not easy to distinguish it in Fig. 8;

- $\quad$ the photovoltaic production (yellow bars in Fig. 8) is higher during the central hours of the day;

- it is necessary to buy a great amount of electricity from the public grid (red bars in Fig. 8) during the entire day;

- the $\mathrm{Na}-\mathrm{NiCl}_{2}$ storage system (green bars in Fig. 8) is charged from 7.45 a.m. to 12 a.m. and discharged in the afternoon.

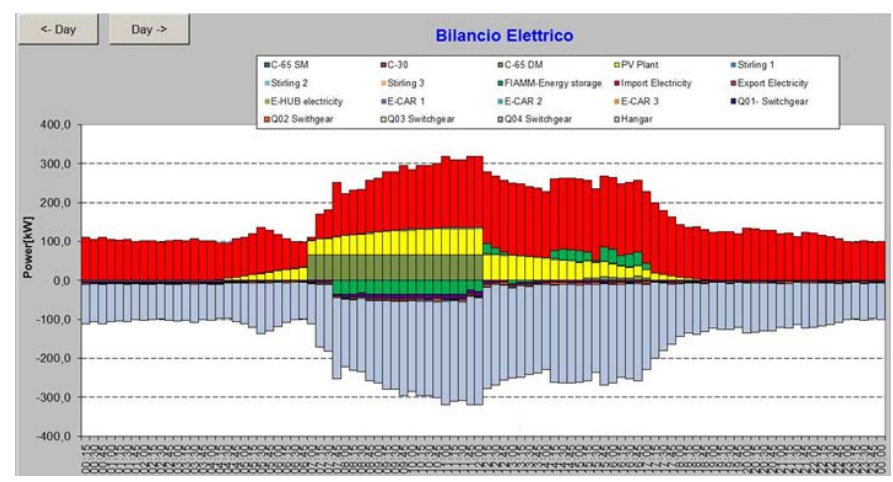

Fig. 8 Savona Campus electrical profiles - July 10, 2015 (Friday).

Different considerations can be drawn referring to a typical winter working day (Friday - February 20, 2015), such as that reported in Figs. 9-10. In Fig. 9 it is possible to notice that the electrical load (in light blue negative bars) attains maximum values (around $250 \mathrm{~kW}$ ) at midday, whereas the base load, slightly higher than $100 \mathrm{~kW}$, occurs during the night. From the electrical point of view (Fig. 9) the power plants are managed as follows: 
- one of the two Capstone C65 microturbines is operation from 6 a.m. to 11 p.m. (blue bars in Fig. 9) and the other from 6.15 a.m. to 10 p.m (olive bars in Fig. 9).

- the Capstone C30 microturbine is off for maintenance;

- the contribution of CSP plants is limited and thus it is not easy to distinguish it in Fig. 9;

- $\quad$ the photovoltaic production (yellow bars in Fig. 9) is higher during the central hours of the day but it is lower than that measured during the summer day plotted in Fig. 8;

- a conspicuous amount of electricity is provided by a microturbine installed in a research laboratory of the University of Genoa (called E-HUB laboratory) from 8 a.m. to 8 p.m. (light green bars in Fig. 9);

- due to the production of the aforesaid microturbines, it is possible to buy a lower amount of electricity from the public grid (red bars in Fig. 9). The absorption of electricity from the public grid is mainly concentrated during the night, when the microturbines are off since no thermal energy is required to heat the buildings;

- the $\mathrm{Na}-\mathrm{NiCl}_{2}$ storage system (green bars in Fig. 9) is charged in hours when the SPM production exceeds the load, whereas it is discharge during the night to limit the electricity withdrawn from the public grid.

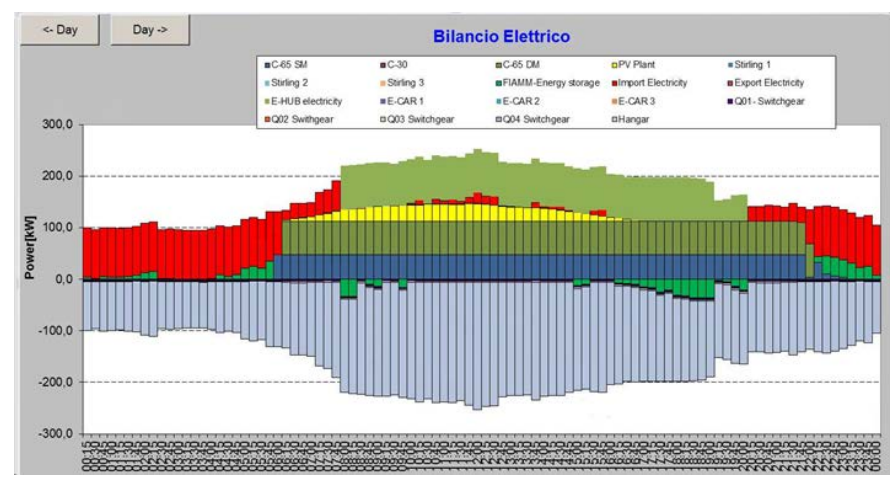

Fig. 9 Savona Campus electrical profiles - February 20, 2015 (Friday).

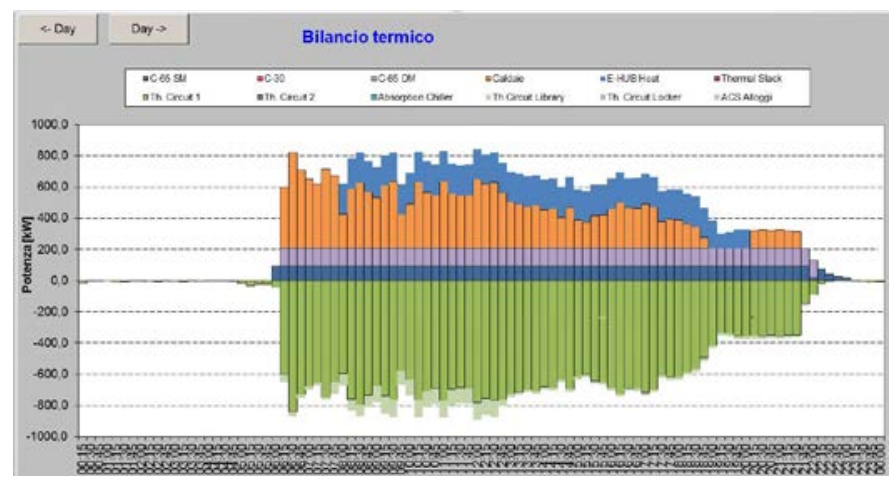

Fig. 10 Savona Campus thermal profiles - February 20, 2015 (Friday).
From the thermal point of view, in Fig. 10 the thermal profiles of microturbines and boilers are reported for the same day analyzed in Fig. 9. The Campus thermal load (given by the sum of negative green and light green bars) is satisfied by the three microturbines (the two Capstone C65 and the one installed in the E-HUB laboratory) and the two boilers. The two Capstone C65 microturbines (blue and violet bars in Fig. 10) and the EHUB microturbine (light blue bars in Fig. 10) mainly operate at full load, while the two boilers modulate.

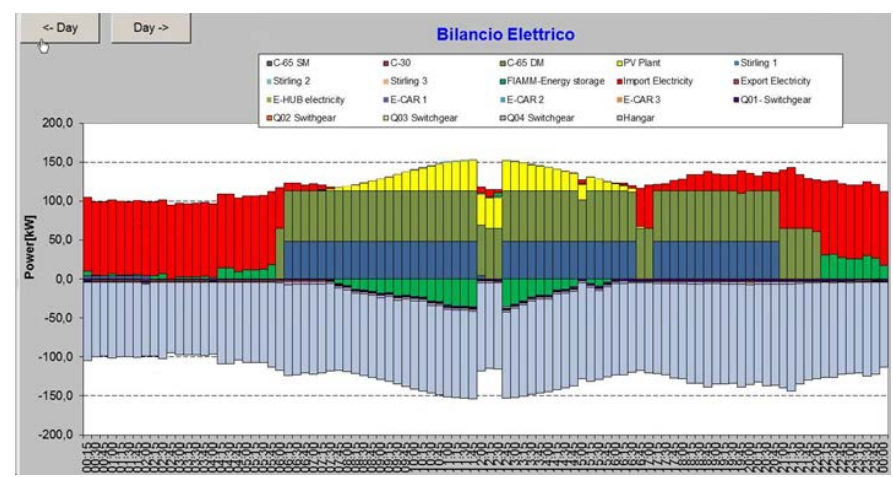

Fig. 11 Savona Campus electrical profiles - February 22, 2015 (Sunday).

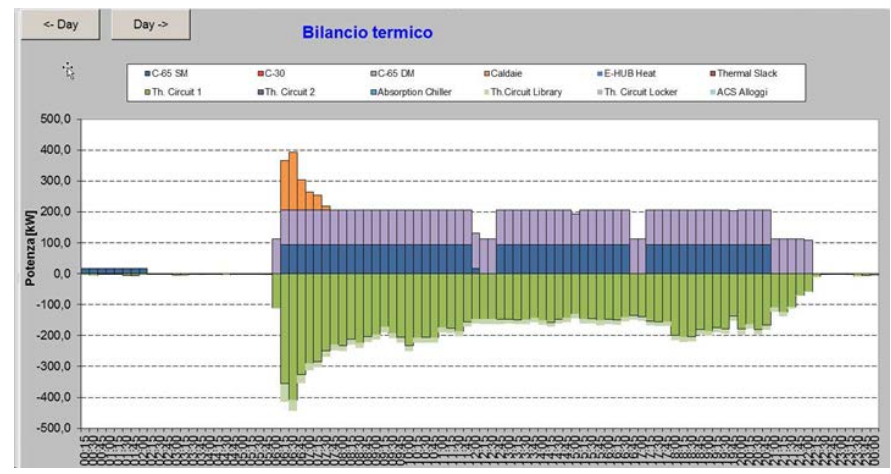

Fig. 12 Savona Campus thermal profiles - February 22, 2015 (Sunday).

In Figs. 11-12 the electrical and thermal load profiles of a typical winter non-working day (Sunday - February 22, 2015) are reported. The electrical load (in light blue negative bars) attains maximum values (around $150 \mathrm{~kW}$, lower than those of a working day) at 11.45 a.m. and 00.45 p.m., whereas the base load of $100 \mathrm{~kW}$ occurs from midnight to 4 a.m. From the electrical point of view (Fig. 11) the power plants are managed as follows:

- one of the two Capstone C65 microturbines is operation from 6 a.m. to 10 p.m. (olive bars in Fig. 11) and the other from 6.15 a.m. to 12 a.m, from 00.45 p.m. to 4.30 p.m. and from 5 p.m. to 8.45 p.m. (blue bars in Fig. 11).

- the Capstone C30 microturbine is off for maintenance;

- the E-HUB microturbine is off since the laboratory is closed on Sunday; 
- the contribution of CSP plants is limited and thus it is not easy to distinguish it in Fig. 11;

- the photovoltaic production (yellow bars in Fig. 11) is higher during the central hours;

- electricity is withdrawn from the public grid (red bars in Fig. 11) during the night and when one of the two Capstone microturbines is off;

- the $\mathrm{Na}-\mathrm{NiCl}_{2}$ storage system (green bars in Fig. 11) is charged in hours when the SPM production exceeds the load (from 7.45 a.m. to 11.45 a.m. and from 00.45 p.m. to 3.45 p.m.), whereas it is discharge during the night to limit the electricity withdrawn from the public grid.

In Fig. 12 it is possible to notice that the thermal load is lower in comparison of that of a winter working day, such as that reported in Fig. 10. The Campus thermal load (given by the sum of negative green and light green bars in Fig. 12) is covered by the two Capstone C65 microturbines and one of the two boilers is used only at the beginning of the morning, due to the load peak.

\section{CONCLUSIONS}

In the present paper the attention has been focused on the "Energia 2020" project developed at the Savona Campus of the University of Genoa, in Italy. In particular the Smart Polygeneration Microgrid and the Smart Energy Building subprojects managed by the Power System Research team of the University of Genoa have been described. Due to the aforesaid projects, the Power System Research team has consolidated skills in the following fields: planning and design of intelligent microgrids; system integration for innovative, sustainable and efficient infrastructures in the energy field; development of Energy Management platforms, for different grid-size applications (nanogrids, microgrids) and different usage (private buildings, industrial); simulation of power/energy systems in off-design and transient operating conditions.

The smart city pilot facilities at the Savona Campus permit to develop research activities on smart microgrids and renewable energy sources in collaboration with universities and companies operating in the energy sector, thus promoting the technical innovation and the fund raising. Moreover, the aforementioned projects have been developed with the aim of raising the awareness of citizens and public authorities about energy efficiency and eco-friendly behaviours. These projects can provide useful guidelines to develop smart microgrids in new residential/tertiary/industrial districts and can be considered as a first step to build a smart city.

\section{REFERENCES}

[1] E. Personal, J.I. Guerrero, A. Garcia, M. Pena, and C. Leon, "Key performance indicators: a useful tool to assess smart grid goals,” Energy, vol. 76, pp. 976-988, 2014.

[2] Q. Qin, Z. Chen, and X. Wang, "Overview of micro-grid energy management system research status,” in Proc. of the 2012 IEEE Power
Engineering and Automation Conference (PEAM), Wuhan, September 18-20, 2012.

[3] F. Martin-Martínez, A. Sánchez-Miralles, and M. Rivier, "A literature review of Microgrids: a functional layer based classification," Renewable and Sustainable Energy Reviews, vol. 62, pp. 1133-1153, 2016.

[4] H. Jiayi, J. Chuanwen, and X. Rong, “A review on distributed energy resources and MicroGrid,” Renewable and Sustainable Energy Reviews, vol. 12, issue 9, pp. 2472-2483, 2018.

[5] E. Hossain, E. Kabalci, R. Bayindir, and R. Perez, "Microgrid testbeds around the world: state of art,” Energy Conversion and Management, vol. 86, pp. 132-153, 2014.

[6] B. Kim, and O. Lavrova, "Optimal power flow and energy-sharing among multi-agent smart buildings in the smart grid,” in Proc. of IEEE Energytech 2013, Cleveland (OH), May 21-23, 2013.

[7] D. Kolokotsa, "The role of smart grids in the building sector," Energy and Buildings, vol. 116, pp. 703-708, 2016.

[8] P. Mancarella, "Distributed multi-generation options to increase environmental efficiency in smart cities," in Proc. of the 2012 IEEE Power and Energy Society General Meeting, pp. 1-8, San Diego, CA, July 22-26, 2012.

[9] G. Chicco, and P. Mancarella, "Distributed multi-generation: a comprehensive view," Renewable and Sustainable Energy Reviews, vol. 13, pp. 535-551, 2009.

[10] S. Bracco, G. Crosa, and A. Trucco, "Dynamic simulator of a combined cycle power plant: Focus on the heat recovery steam generator,” in Proc. of the 20th International Conference on Efficiency, Cost, Optimization, Simulation and Environmental Impact of Energy Systems (ECOS 2007), vol. 1, pp. 189-196, Padova, Italy, June 25-28, 2007.

[11] P.D. Lund, J. Mikkola, and J. Ypya, "Smart energy system design for large clean power schemes in urban areas," Journal of Cleaner Production, vol. 103, pp. 437-445, 2015.

[12] C. Chen, S. Duan, T. Cai, B. Liu, and G.Hu, "Smart energy management system for optimal microgrid economic operation,” IET Renewable Power Generation, vol. 5, issue 3, pp. 258-267, 2011.

[13] W. Su, and J. Wang, "Energy Management Systems in microgrid operations,” The Electricity Journal, vol. 25, issue 8, pp. 45-60, 2012

[14] S. Bracco, F. Delfino, F. Pampararo, M. Robba, and M. Rossi, "A pilot facility for analysis and simulation of smart microgrids feeding smart buildings," Renewable and Sustainable Energy Reviews, vol. 58, pp. 1247-1255, May 2016.

[15] S. Bracco, F. Delfino, F. Pampararo, M. Robba, and M. Rossi, "A dynamic optimization-based architecture for polygeneration microgrids with tri-generation, renewables, storage systems and electrical vehicles," Energy Conversion and Management, vol. 96, pp. 511-520, 2016.

[16] S. Bracco, G. Dentici, and S. Siri, "DESOD: A mathematical programming tool to optimally design a distributed energy system," Energy, vol. 100, pp. 298-309, 2016.

[17] C.F. Calvillo, A. Sanchez-Miralles, and J. Villar, "Energy management and planning in smart cities," Renewable and Sustainable Energy Reviews, vol. 55, pp. 273-287, 2016.

[18] S. Bracco, M. Brenna, F. Delfino, F. Foiadelli, and M. Longo, "Sustainable electric mobility analysis in the Savona Campus of the University of Genoa," in Proc. of $16^{\text {th }}$ IEEE International Conference on Environment and Electrical Engineering, Florence, Italy, June 7-10, 2016.

[19] J. Soares, N. Borges, M.A. Fotouhi Ghazvini, Z. Vale, and P.B. de Moura Oliveira, “Scenario generation for electric vehicles' uncertain behavior in a smart city environment,” Energy, vol. 111, pp. 664-675, 2016.

[20] S. Bracco, F. Delfino, F. Pampararo, M. Robba, and M. Rossi, “A system of systems model for the control of the University of Genoa Smart Polygeneration Microgrid," in Proc. Of 7th International Conference on System of Systems Engineering (SoSE 2012), Genoa, Italy, July 16-19, 2012. 